\title{
Pressure bandages after coronary angiography reduced bleeding, but increased discomfort
}

\author{
Botti M, Williamson B, Steen K, et al. The effect of pressure bandaging on complications and comfort in patients undergoing \\ coronary angiography: a multicenter randomized trial. Heart Lung 1998 Nov/Dec;27:360-73.
}

\section{Question}

What is the effectiveness and safety of pressure bandages applied immediately after coronary angiography?

\section{Design}

Randomised controlled trial with follow up at 6-12 hours after the procedure.

\section{Setting}

1 private and 2 public university hospitals in Melbourne, Australia.

\section{Patients}

1075 patients (mean age 61.4 y, $69 \%$ men) who had coronary angiography. Patients were excluded if they were unable to give written consent or if their cardiologist did not want them to participate.

\section{Intervention}

Randomisation was stratified across the 3 hospitals. After the coronary angiography procedure was completed and once haemostasis was achieved through $\geqslant 10$ minutes of manual compression, patients were allocated to the pressure bandage $(n=519)$ or to no pressure bandage $(n=556)$. Patients in the pressure bandage group had a wad of 8 gauze squares placed over the femoral puncture site and held in place by a 2 metre elasticised non-adhesive blue line bandage applied in a figure 8 formation around the leg and across the lower abdomen and back. The bandage remained in place for 6-12 hours. Patients in the no bandage group had either an adhesive bandage or no covering at all on the puncture site.

\section{Main outcome measures}

Bleeding, bruising, and measures of patient discomfort (nausea; groin, back, and leg pain; and urinary difficulties).

\section{Main results}

Analysis was by intention to treat. Patients in the bandage group had a lower incidence of bleeding (table) and bled later than patients in the no bandage group (mean $5.3 v 2.4 \mathrm{~h}$ after procedure, $\mathrm{p}<0.001$ ), but did not differ for incidence and size of bruising. Patients in the bandage group had a higher incidence of nausea, back pain, groin pain, leg pain, and urinary difficulties (table); they reported a higher intensity of groin pain $(\mathrm{p}<0.05)$, but not leg or back pain.

\section{Conclusions}

Patients who had a pressure bandage applied after coronary angiography had a lower incidence of bleeding and a longer time to bleeding than patients who had no pressure bandages, but did not differ for bruising. Patients with pressure bandages had more nausea, groin pain, back pain, leg pain, and urinary discomfort.

Pressure bandage $v$ no pressure bandage at 6-12 hours after coronary angiography*

\begin{tabular}{|c|c|c|c|c|}
\hline Outcomes & $\begin{array}{l}\text { Pressure } \\
\text { bandage }\end{array}$ & $\begin{array}{l}\text { No pressure } \\
\text { bandage }\end{array}$ & $R R R(95 \% C I)$ & $N N T(C I)$ \\
\hline Bleeding & $3.5 \%$ & $6.7 \%$ & $47.9 \%$ (10.4 to 69.8$)$ & $32(17$ to 175$)$ \\
\hline Outcome & $\begin{array}{l}\text { Pressure } \\
\text { bandage }\end{array}$ & $\begin{array}{l}\text { No pressure } \\
\text { bandage }\end{array}$ & $R R I(95 \% C I)$ & $N N H(C I)$ \\
\hline Nausea & $5.6 \%$ & $2.7 \%$ & $107 \%(13.5$ to 279$)$ & 35 (19 to 188$)$ \\
\hline Back pain & $26.6 \%$ & $21.0 \%$ & $26.4 \%(1.9$ to 56.7$)$ & $19(10$ to 220$)$ \\
\hline Groin pain & $17.5 \%$ & $4.7 \%$ & $275 \%$ (148 to 469$)$ & $8(6$ to 11$)$ \\
\hline Leg pain & $8.7 \%$ & $2.2 \%$ & $302 \%(118$ to 645$)$ & $16(11$ to 26$)$ \\
\hline $\begin{array}{l}\text { Urinary } \\
\text { difficulties }\end{array}$ & $16.8 \%$ & $9.9 \%$ & $69.5 \%$ (24 to 132$)$ & $15(10$ to 36$)$ \\
\hline
\end{tabular}

*Abbreviations defined in glossary; RRR, RRI, NNT, NNH, and CI calculated from data in article.

Source of funding: no external funding.

For correspondence: Dr M Botti, School of Nursing, Deakin University, 221 Burwood Highway, Burwood, Victoria 3125, Australia. Fax +61392446159

\section{Commentary}

For years, bedside nursing staff have been asking questions about the different femoral puncture site dressings that are seen in clinical practice. Most often, dressing type depends on cardiologist preference. Clinically, questions have arisen about dressing types and their relation to complications and patient comfort. There has been a recent change in practice towards the decreased use of pressure dressings. This change, however, has been grounded in clinical observation, without a strong research base. Although other studies have looked at ambulation and patient positioning after angiography, studies about femoral puncture site dressings have been limited. Botti et al compared patients with and without pressure dressings after coronary angiography. The study describes the incidence of patient discomfort and complications such as bleeding and haematoma formation. It would have been interesting if the authors had reported on the vasovagal incidence (a fainting response that can occur because of manual manipulation or pressure on nerves in the groin area) and the relation between leg pain and peripheral vascular disease because compression may further reduce circulation in the leg (ie, it may cause increased leg pain).

The study had sufficient power to detect group differences and used intention to treat analysis. One limitation may be the potential variability in the measurement of bruises because of the difficulties in obtaining precise measures of irregularly shaped bruises and because of the large number of people doing the measurements.
This study shows that pressure dressings should not be routinely used after angiography. Pressure dressings were associated with increased patient discomfort and delayed bleeding. Because the average duration of hospital stays seems to be decreasing, the implications for patients experiencing delayed bleeding after discharge should be explored. In addition, this study provides support for practice in other patient populations with femoral puncture sites, such as patients who have intra-aortic balloon procedures.

Marlene Donahue, RN, MN Clinical Coordinator, Cardiac Surgery Foothills Medical Centre Calgary, Alberta, Canada 